\title{
Planning and Implementing an Online Undergraduate Medical Student Selection Exercise during the COVID-19 Pandemic: Experience of the School of Medical Sciences, Universiti Sains Malaysia
}

Submitted: 19-07-2020

Accepted: 23-09-2020

\author{
Ahmad Fuad Abdul Rahim ${ }^{1}$, Mohamad Najib Mat Pa', Jamilah Al- \\ Muhammady Mohammad', Kamarul Aryffin Baharuddin', Muhamad \\ Saiful Bahri Yusoff', Muhd Al-Aarifin Ismail', Nor Azman Mat Zin² \\ ${ }^{1}$ Department of Medical Education, School of Medical Sciences, \\ Universiti Sains Malaysia, Kelantan, MALAYSIA \\ ${ }^{2}$ Department of Orthopedics, School of Medical Sciences, Universiti \\ Sains Malaysia, Kelantan, MALAYSIA
}

To cite this article: Abdul Rahim AF, Mat Pa MN, Mohammad JA-M, Baharuddin KA, Yusoff MSB, Ismail MA-A, Mat Zin NA. Planning and implementing an online undergraduate medical student selection exercise during the COVID-19 pandemic: experience of the School of Medical Sciences, Universiti Sains Malaysia. Education in Medicine Journal. 2020;12(4):33-42. https://doi. org/10.21315/eimj2020.12.4.5

To link to this article: https://doi.org/10.21315/eimj2020.12.4.5

\section{ABSTRACT}

This article described the context, planning and implementation of a video-conference-based undergraduate student selection exercise held in response to restrictions during the COVID-19 pandemic. A task force has brainstormed the ideas and decided a face-to-face interview using a video conferencing application which was the best way to achieve the objective set for the exercise. Facilitators communicated with interviewers and candidates, and hosted video meetings between the two parties. Interviewers were trained using online videos, a webinar and a trial run. They rated candidates using a printed rating instrument as well as an online form. About 615 candidates were interviewed in this study. Initial impressions were positive and will be followed-up by a proper evaluation.

Keywords: Online, Medical student, Selection exercise, COVID-19, Experience Universiti Sains Malaysia, 16150 Kubang Kerian, Kelantan, Malaysia | Email: drnajib@ usm.my

\section{INTRODUCTION}

Education including medical training have had to adapt itself to the sweeping changes brought about by the COVID-19 (1) pandemic. Going online for teaching and learning have been the almost universal strategy adopted by educational institutions the world over $(2,3)$. For the School of Medical Sciences (SMS), Universiti Sains Malaysia, the online approach was also the strategy used to handle another important event in its educational calendar: student selection. 
As a reference, the first case of COVID-19 was reported in Malaysia on the 25th January 2020 (4). Following the COVID-19 pandemic declaration by the World Health Organisation (WHO) on 11 th March 2020, a nationwide ban on mass gatherings and the temporary closure of schools were announced on the 13th March 2020 with universities closely following suit (5). A movement control order (MCO) was subsequently enforced on the 18th March 2020 (6).

These nationwide measures came when the SMS was preparing for its student selection exercise; a huge yearly undertaking. For the current year, about 615 candidates qualified for the interview after fulfilling academic prerequisites. Due to the MCO, a new student selection process was needed for the school to look at candidates' non-cognitive attributes as well as to whittle down the numbers to fill the 125 seats available.

In this article, the context of the student selection process in the SMS during this COVID-19 pandemic is described and the experience in planning and implementing the procedure is shared. It is hoped that this article will benefit similar institutions facing the same challenge.

\section{CONTEXT}

Selection interviews for entry into undergraduate courses in Malaysian public universities are under the purview of the national University Admissions Unit (UAU), which coordinates the application and intake of eligible applicants into universities nationwide. The UAU determines the period for interviews after a meeting with all public universities. The meeting was held after the MCO was enforced; it was decided that the interviews are to be done in the early May 2020. This gave the SMS less than two months to prepare a new strategy of student selection. The Deputy Dean of Academic, Career and International Affairs appointed a director to lead a task force to brainstorm, plan and implement the new student selection exercise. The priority of the task force was to choose a proper student-selection process that was: (a) congruent with the objectives for the student selection exercise, and (b) feasible to implement within the narrow time window to produce an acceptedcandidates list.

The SMS has been using the multiple mini interview (MMI) since 2016, after considering the merits of the selection procedure (7). Therefore, an online version of MMI was an early consideration. Tiller et al. reported an online MMI procedure, named the iMMI, used in the University of Sydney (8). After deliberations, a similar method was not used for two reasons. First, the total number of candidates was 615, far more than the 293 candidates interviewed in Sydney. The second was the issue of feasibility. The iMMI reversed the MMI process: instead of candidates going around a circuit of interview stations, it is the interviewers who rotate around a circuit of computers with candidates logged on in each computer. Replicating this process for the SMS requires procuring new computers, extra technical personnel, and arguably the most important, more time to explain to and train faculty interviewers. In short, time was not sufficient for us to plan, prepare and implement a similar exercise.

Rating short video recordings of participants in which they explain their reasons for deciding to do medicine was considered. After some discussions, this idea was rejected as it precluded the element of spontaneity, which regarded as essential in assessing the domains such as problemsolving and demeanour. It is also feared that video recordings would unfairly favour candidates with excellent presentation skills or those with access to proper video recording and editing hardware and software.

Before using the MMI, however, the SMS utilised a face-to-face interview process. It began in 2009 after a long period of accepting candidates based 
purely on academic merit (9). This was a more "traditional" interview where each candidate faced two interviewers for a period of 15 to 20 minutes. Its objective was to look at non-cognitive attributes, including communication skills, motivation and problem-solving in candidates who were already screened in terms of their cumulative grade point average (CGPA) (9). The same objective was also continued in the previous MMI-based student selection exercises. Therefore, it was important that the new interview format maintains the same objective. The most suitable strategy to achieve this was an online, interactive and synchronous (real-time) method. Besides, a rating instrument was already developed for this previous interview, thus allowing its conversion into a condensed online-interview rating instrument. This process was more straightforward compared to creating a new rating instrument from scratch. Based on studies by Yusoff (9) and Yusoff et al. (10), there were evidence that students interviewed using the faceto-face interview fared better in academic performance and clinical examination compared to non-interviewed students. For these reasons, the task force finally decided an online interview that closely followed the previous face-to-face format was the best method that met the priority.

\section{PLANNING AND IMPLEMENTATION}

\section{Composition of the Student Selection Task Force}

The task force was advised by the Deputy Dean of Academic, Career and International Affairs, SMS. He also acted as the primary liaison in communication with the student admissions unit at the university level. The task force director was in charge of overall organisation and coordination of the whole exercise and was deliberately designated as the main person in communication with interviewers to keep information consistent and non-conflicting. The academic deputy registrar assisted the director and was in charge of the overall candidate list and the candidate hotline. She was supported by the chief clerk of the academic office. Apart from this core group of people, another group from the Department of Medical Education looked into matters such as data collation and cleaning. A faculty member with extensive experience in information and communication technology assisted in technical issues.

\section{Video Conferencing Application}

The issue of security is the primary concern in an online interview. The best security practices must be followed. In this regard, the usage of a certified and secure application is mandatory. It was fortunate that the school already has an institutional licence for the Cisco Webex video conferencing application which is a FedRAMP (11) and an ISO 27001 certified (12) product. It became a natural application of choice for the interview exercise. It places non-recognised participants in a virtual "lobby", outside of the meeting, and gives the meeting host the authority to admit from the lobby or remove any particular member from the meeting. This capability is ideal for an interview situation where the host can accept candidates one-by-one into a meeting with interviewers and remove them when the interview is over.

The application's ability to record the interview was utilised. Recording is necessary in case that any enquiries should arise later. To this end, candidates were informed verbally and in writing that the interview was going to be recorded. All recordings were transferred to an external hard disk after each session and stored in a secure location.

\section{Interviewers}

As in the previous years, the interviewers were from the faculty volunteers. The task force director circulated an official invitation for volunteers in the school 
intranet together with a link to a Google Form where volunteers can choose the interview date and session they preferred. This year was different as interviewers could participate from their remote sites, either from their own offices or homes due to the work-from-home policy. The online format enabled involvement of faculty from remote locations. Invitation for interviewers was extended to colleagues in the Advanced Medical and Dental Institute, a sub-campus approximately 300 kilometres away. All interviewers signed a declaration of interest form, which was sent via WhatsApp. Both printed and digitally signed forms were accepted.

\section{Candidates}

The list of candidates for the interview came from the UAU. From the large pool of applicants who have already met the academic prerequisite criteria, the Universiti Sains Malaysia received 615 candidates to vie for the 125 seats in medicine course. A Facebook page was created for communicating general information regarding the interview. Specific WhatsApp groups were also organised according to the interview schedule.

\section{Interview Schedule}

Seven working days were allocated for the interview to cater to the significant number of candidates. Each interview day was divided into morning and afternoon sessions and numbered consecutively, from the morning session 1 to the afternoon session 14 of the seventh day. Candidates were distributed among the seven days, and they were further divided into the sessions for each day. In each session, they were slotted into one of eight groups, named A to $\mathrm{H}$. The interview date, session, group and interview time for each candidate were sent to candidates via WhatsApp. Similarly, interviewers who volunteered for any particular session were randomly assigned to any one of the groups. As the interview looked at general non-cognitive domains, no special considerations such as clinical- nonclinical or male-female were given in the pairing of interviewers.

This scheduling meant that at any particular time, eight candidates were interviewed concurrently in eight video meetings; each meeting comprising of two interviewers, the candidate and an interview facilitator. Candidates were scheduled so that the interviewer pairs in each group saw approximately eight to nine candidates in the morning sessions or four candidates in the afternoon sessions, to ensure that the 615 candidates were interviewed over the seven days in a relaxed pace. A summary of the interview schedule is given in Table 1 .

Table 1: Summary of the interview schedule.

\begin{tabular}{ccc}
\hline & \multicolumn{2}{c}{ Sessions } \\
\cline { 2 - 3 } Day & $\begin{array}{c}\text { Morning } \\
\text { (8-9 candidates) }\end{array}$ & $\begin{array}{c}\text { Afternoon } \\
\text { (3-4 candidates) }\end{array}$ \\
\hline Day 1 & Session 1 (A-H) & Session 2 (A-H) \\
Day 2 & Session 3 $(\mathrm{A}-\mathrm{H})$ & Session 4 $(\mathrm{A}-\mathrm{H})$ \\
Day 3 & Session 5 $(\mathrm{A}-\mathrm{H})$ & Session 6 $(\mathrm{A}-\mathrm{H})$ \\
Day 4 & Session 7 $(\mathrm{A}-\mathrm{H})$ & Session 8 $(\mathrm{A}-\mathrm{H})$ \\
Day 5 & Session 9 $(\mathrm{A}-\mathrm{H})$ & Session 10 $(\mathrm{A}-\mathrm{H})$ \\
Day 6 & Session 11 $(\mathrm{A}-\mathrm{H})$ & Session 12 $(\mathrm{A}-\mathrm{H})$ \\
Day 7 & Session 13 $(\mathrm{A}-\mathrm{H})$ & Session 14 $(\mathrm{A}-\mathrm{H})$ \\
\hline
\end{tabular}

\section{Interview Process}

Before the interview started, each candidate had to show their identification card to verify their identity. Each candidate was given 15 to 20 minutes for the interview. Interviewers verbally asked questions and listened to candidates' answers while simultaneously observing their body language, appearance and demeanour. For problem-solving, candidates were shown case scenarios online and were asked to discuss them. These case scenarios were changed daily and given to the interviewers via WhatsApp at the beginning of each session. As mentioned previously, all interview sessions were recorded and saved for future reference. A summary of the interview process is given in the Figure 1. 


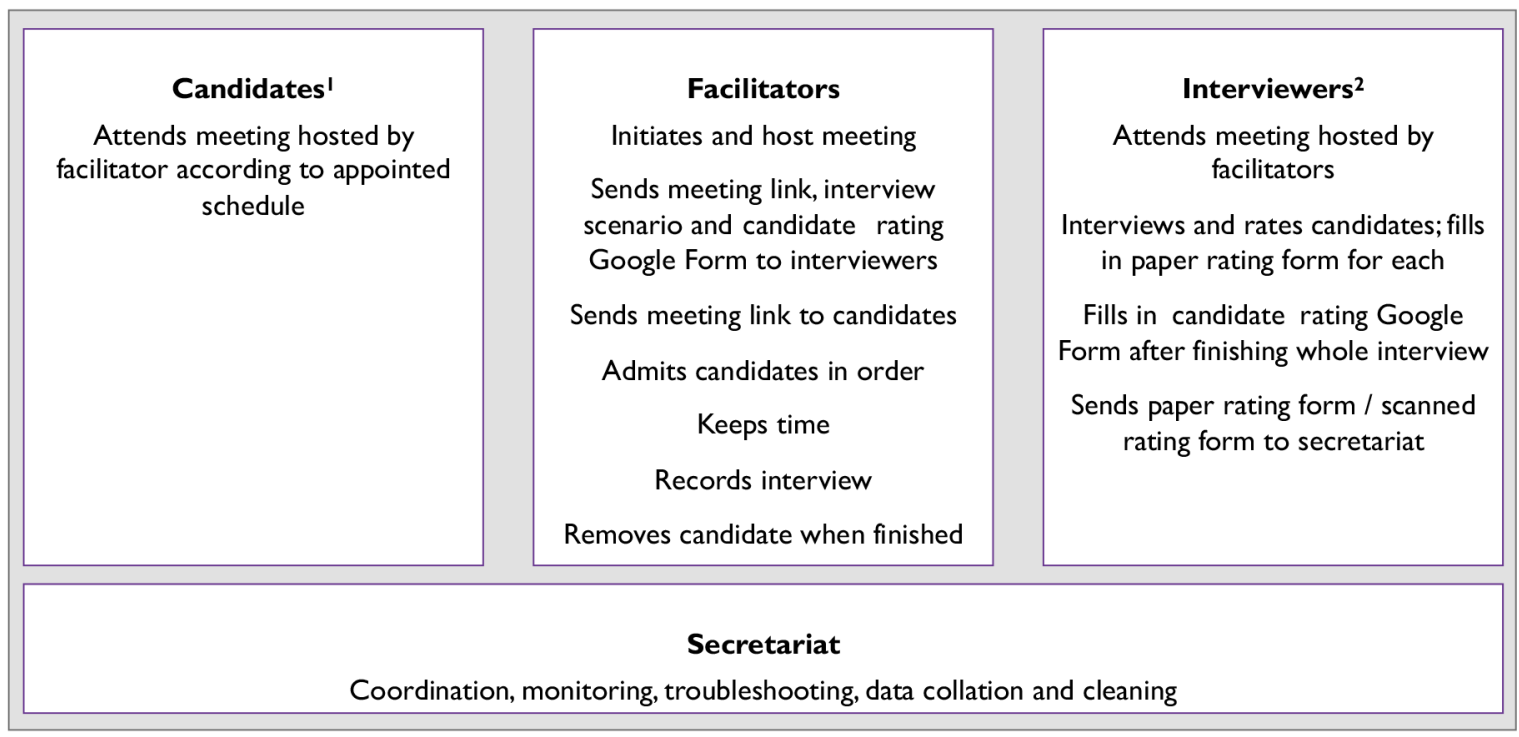

'Distributed over seven days, two sessions per day in each session slotted into one of eight concurrent groups. Attends interview remotely.

${ }^{2}$ Slotted into session of choice, assigned to one of eight groups. Attends interview remotely.

Figure 1: A summary diagram of the interview process.

\section{Rating Process}

The rating instrument "SMS undergraduate student selection rating form" (Figure 2) consisted of a section for interviewer and candidate details and a rating scale from 1 to 10 for each of the domains. Behavioural descriptors of the highest and the lowest performance were given for each domain. A global rating of "accepted", "borderline" and "not accepted" was also provided. Space for subjective comments was provided for the global rating.

Interviewers were given a soft copy of the rating instrument online and were asked to print sufficient copies to be used during the interview. This instruction was to help interviewers who did not feel comfortable filling an online form while interviewing candidates. Some interviewers preferred printed rating forms for writing subjective comments. It also facilitated interviewers to revise their ratings.

Interviewers were also provided links to candidate rating Google Form, which contained fields identical to the printed form. They were asked to fill in and submit these online forms, one for each candidate, after finishing interviewing all their candidates. This step replaced the role of a dedicated group of data-entry assistants used in the previous years' exercises; this saved time and further reduced the number of personnel involved. To facilitate the data cross-checking, interviewers were asked to hand in their printed forms to the secretariat. Those interviewing from remote sites were asked to scan their paper rating forms using a PDF scanner in their smartphones and send it online to the secretariat via email or WhatsApp.

The candidate rating Google Form was the central database for the interview. The student selection task force was able to view the data entry in "real-time" as interviewers filled in the forms daily. Data cleaning was completed very soon after the interview exercise finished. This included checking for discrepancies in the data by comparing it with data in the hard-copy forms sent in at the end of each session or via the internet.

The candidates were ranked according to their total of four domains, averaged from the two interviewers. The global rating and 
subjective comments were consulted in cases of a tie in the total marks. After the final list of accepted candidates was produced, it was presented to the Dean of SMS for his agreement. The list was then sent to the student admissions unit.

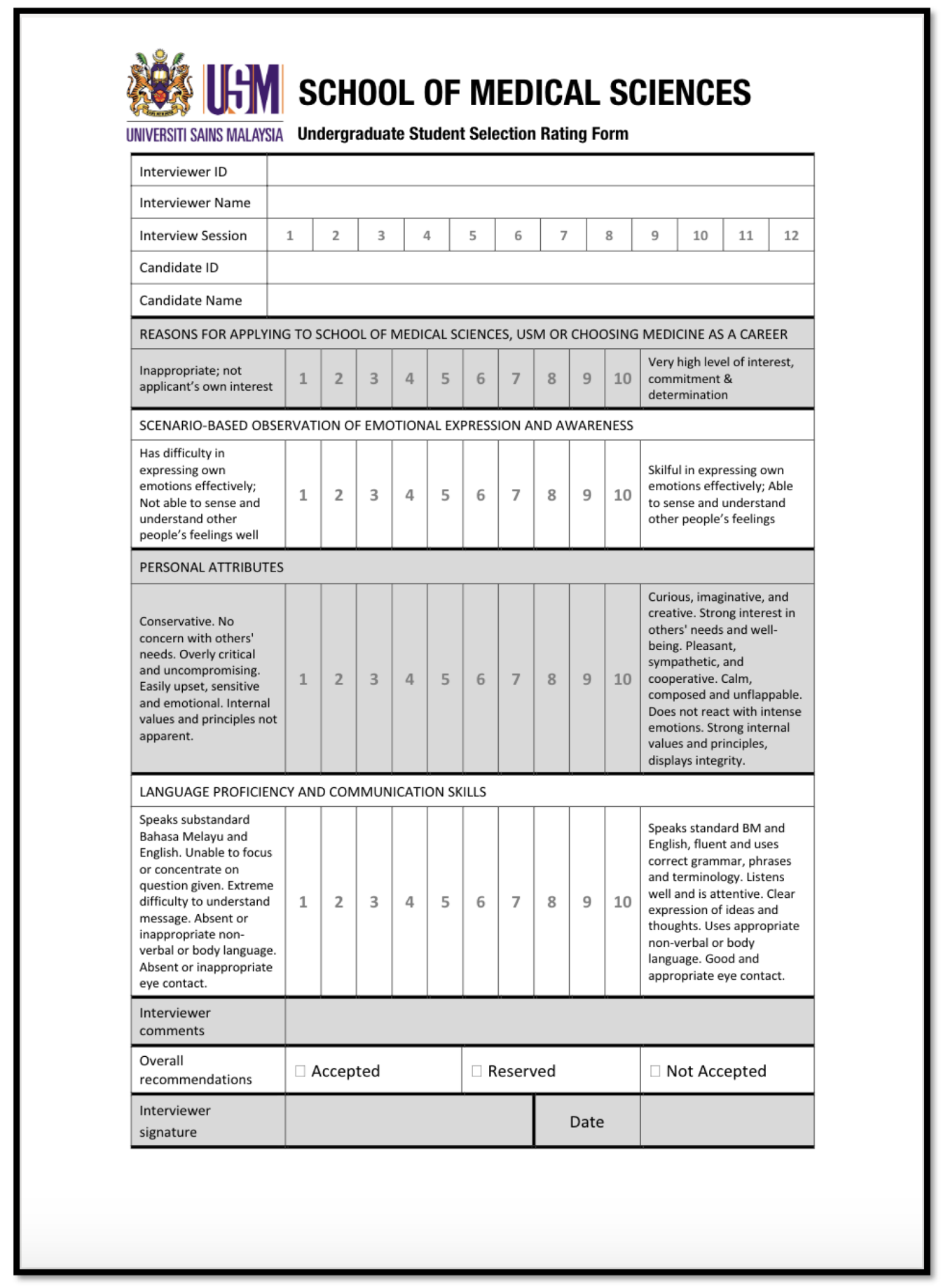

Figure 2: The interview rating form. 


\section{Interview Facilitators}

The shift to emergency remote teaching precipitated by the COVID-19 pandemic has taught that utilising new and unfamiliar information and communication technology can be an issue for some faculty members (13). This study found that some interviewers would be intimidated by video conference technology, not to mention the new process and procedures. To alleviate this situation and simplify the interview process for interviewers, the post of interviewer facilitators was created.

These facilitators worked in pairs. Eight pairs were nominated; a pair for each interview group. They were on duty throughout the seven days of the interview and were assigned to a pair of interviewers for each morning and afternoon interview sessions. The roles of these facilitators were to initiate and host the video meeting between interviewers and candidates. They sent the meeting links via WhatsApp to interviewers assigned to them. In this way, interviewers did not have to initiate the meeting but just clicked on the meeting link. Facilitators also communicated with candidates in the corresponding groups and sent the same video meeting links to them. They have to make sure that the candidates joined the meeting at their prescribed times, by entering the meeting "lobby" and only admitted the candidates into the meeting once the interviewers were ready. They also reminded interviewers regarding the time and were also responsible for recording the sessions. After an interview session has finished, they removed the candidate from the meeting.

\section{Interview Venue}

A significant difference in this year was the absence of a physical venue for the interview. All facilitators and task force members operated in a central location to facilitate monitoring and technical assistance by the task force members. Continuous data collation and cleaning was also done at the centre. Some rooms with internet facilities were prepared for interviewers who preferred to be closed to the task force during interviews.

\section{Documentation and Training}

For candidates: A document explaining the running of the interview was sent to candidates before their interview. It included instructions to prepare laptops with functioning video cameras and microphones, and with Cisco Webex and WhatsApp Web installed. Candidates needed to test the speed of their internet connection and find alternative sites if the rate was less than $5 \mathrm{Mbps}$. They were also informed regarding honesty during the interview, policies regarding cheating and that the interview will be recorded.

For interviewers: As an observer-based assessment that depended on interviewers' judgement, the most critical component was training to familiarise interviewers to the domains and rating form used (performance dimension training) and to calibrate their judgement (frame-ofreference training) $(14,15)$. Interviewers were included in a WhatsApp group to facilitate communication with the task force. A series of YouTube videos were prepared, explaining in detail the process of the interview, the domains involved and the usage of the rating instrument as well as relevant topics such as rater errors. A video example of an "excellent" candidate was included to give interviewers a frame of reference. A webinar was held a few days before the session, followed by a dry run, which allowed interviewers to test their equipment, get to know their facilitators and experience procedures such as sharing documents in the video meeting.

For facilitators: Facilitators were given a briefing where roles and processes were explained. The procedures of handling the software were shown using an LCD projector and a hands-on session was done simultaneously with the dry run. 
A summary of the personnel involved in the interview session is given in Table 2 and a summary of the complete online interview process is shown in Figure 3.

Table 2: Summary of personnel involved in the interview

\begin{tabular}{|c|c|c|}
\hline Personnel & Number & Roles \\
\hline Task force director & 1 & $\begin{array}{l}\text { Coordinate the whole interview process } \\
\text { Communicate with interviewers }\end{array}$ \\
\hline Interview facilitator & 16 & To facilitate the process of interview \\
\hline Medical educationist & 10 & $\begin{array}{l}\text { Train the interviewers and facilitators } \\
\text { Prepare rating instrument } \\
\text { Prepare interview scenarios } \\
\text { Ensure the validity of the assessment } \\
\text { Ensure all data captured in the system } \\
\text { Trace all missing data } \\
\text { Analyse data }\end{array}$ \\
\hline Secretariat & 2 & $\begin{array}{l}\text { Communication with candidates (hotline) } \\
\text { Coordinate other matters } \\
\text { To help facilitators in term of technicalities } \\
\text { Back-up facilitators }\end{array}$ \\
\hline Interviewer & 165 & Conduct interview and rate candidates \\
\hline
\end{tabular}

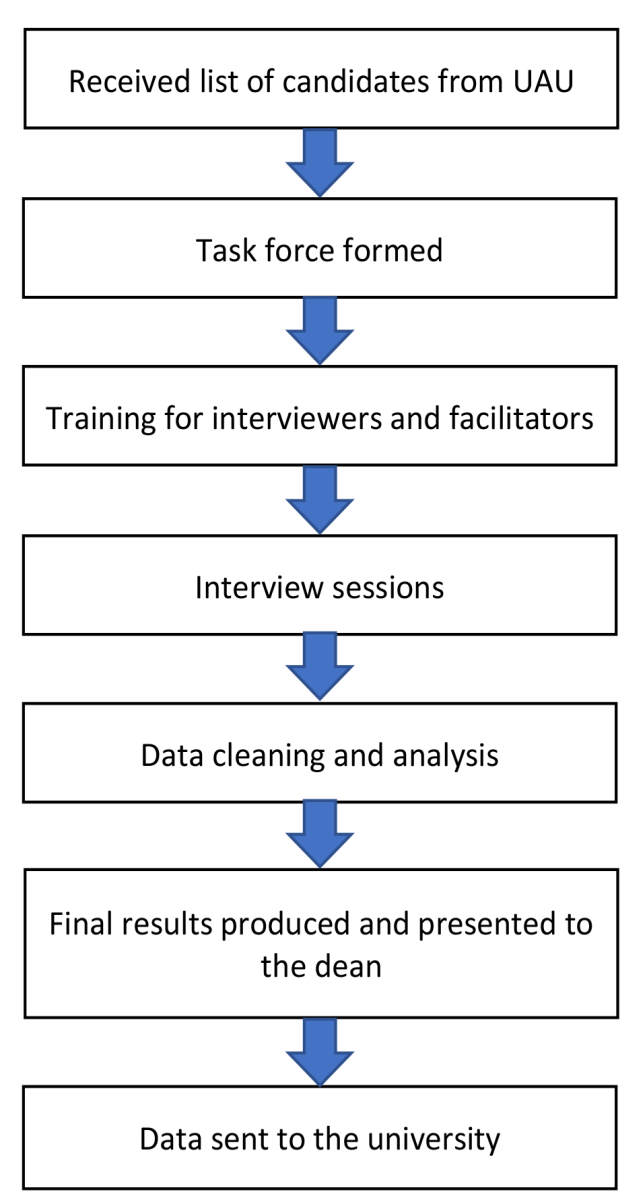

Figure 3: Summary of the whole interview process. 


\section{LESSONS LEARNT}

Online interviews are quite established in the qualitative research and employment (16). However, scant literature reporting the use of online interviews for student selection in medicine was found. On the face of it, the interview appeared to be a success with some apparent advantages over the traditional face-to-face interview. These included the significant reduction of expenses both for the SMS and candidates. This online interview did not have to prepare the physical interview venue, which was a major logistical undertaking in the previous yearly preparations. Interviewers and candidates also appeared to appreciate the flexibility regarding the site of the interview. Initially, there was a fear amongst interviewers of candidate cheating such as getting prompts from off-camera sources. Still, during the actual exercise, interviewers reported very few instances of suspected cheating. There were some instances of internet disruptions, but its occurrence was far less than anticipated. The disruptions were successfully managed by a backup procedure of interview using WhatsApp video conferencing. No interview was postponed to a later date due to internet or other problems.

Faculty buy-in for the new procedure was better than anticipated. This might be due to increased acceptance of faculty to online communication technology due to the general migration to online teaching and learning methods during the COVID-19 pandemic.

There was concern that the interview method excluded candidates with limited access to internet infrastructure and facilities. However, it was felt that this method was the best that can be offered given the current scenario and considering all variables.
These initial positive impressions as well as concerns need to be explored and confirmed with further evaluation of the acceptability, effectiveness and educational impact of the online personal interview selection process. Further validity evidence supporting its practice needs to be provided.

The positive initial findings predict a high likelihood that the online interview will continue to be used in the coming years, and research into iMMI which can cater for a large number of candidates is a likely next step.

\section{CONCLUSION}

Initial impressions suggest that an online face-to-face student selection process, using the methods described, is feasible even for a large number of candidates and acceptable to interviewers and candidates. Further evaluations are needed to establish the validity of the process.

\section{REFERENCES}

1. Geske D. WHO gives Coronavirus official name: what does COVID-19 mean? [Internet]. International Business Times. 2020 [cited 2020 August 24]. Available from: https://www.ibtimes.com/who-givescoronavirus-official-name-what-does-covid19-mean-2920160

2. UNICEF. Heading back to school in the pandemic [Internet]. 2020 [cited 2020 August 24]. Available from: https://www. unicef.org/coronavirus/heading-back-schoolin-pandemic

3. Crawford J, Butler-Henderson K, Rudolph J, Malkawi B, Glowatz M, Burton R, et al. COVID-19: 20 countries' higher education intra-period digital pedagogy responses. J Appl Learn Teach. 2020;3(1):9-28. https:// doi.org/10.37074/jalt.2020.3.1.7 
4. The Straits Times. Coronavirus: Malaysia confirms first case with travel history to Japan, SE Asia News \& Top Stories. 2020 February 27 [cited 2020 April 15]. Available from: https://www.straitstimes.com/asia/ se-asia/malaysia-confirms-1 st-case-ofcoronavirus-with-travel-history-to-japan

5. Lim I. Covid-19: what are Malaysia's public universities doing? Online classes and more... Malay Mail. 2020 March 16 [cited 2020 June 28]. Available from: https://www. malaymail.com/news/malaysia/2020/03/16/ covid-19-what-are-malaysias-publicuniversities-doing-online-classes-and$\mathrm{mo} / 1847071$

6. Wikipedia. 2020 Malaysia movement control order. 2020 [cited 2020 June 14]. Available from: https://en.wikipedia.org/wiki/2020_ Malaysia_movement_control_order\#cite_ note-MCO_contents-5

7. Abdul Rahim AF, Yusoff MSB. Validity evidence of a multiple mini interview for selection of medical students: Universiti Sains Malaysia experience. Education in Medicine Journal. 2016;8(2):49-63. https:// doi.org/10.5959/eimj.v8i2.437

8. Tiller D, O'Mara D, Rothnie I, Dunn S, Lee L, Roberts C. Internet-based multiple mini-interviews for candidate selection for graduate entry programmes. Med Educ. 2013;47(8):801-10. https://doi.org/10.1111/ medu. 12224

9. Yusoff MSB. The outcomes that an interview-based medical school admission process has on academic performance, psychological health, personality traits, and emotional intelligence. J Taibah Univ Med Sci. 2018;13(6):503-11. https://doi. org/10.1016/j.jtumed.2018.09.003
10. Yusoff MSB, Rahim AFA, Baba AA, Esa AR. Medical student selection process and its pre-admission scores association with the new students' academic performance in Universiti Sains Malaysia. Int Med J. 2011;18(4):329-33.

11. CISCO. FedRAMP Authorized Solutions. n.d. [cited 2020 July 16]. Available from: https://www.cisco.com/c/en/us/solutions/ industries/government/federal-governmentsolutions/fedramp.html

12. CISCO. ISO 27001 - Information Security Certifications. n.d. [cited 2020 July 16]. Available from: https://www.cisco.com/c/en/ us/about/approach-quality/iso-27001.html

13. Abdul Rahim AF. Guidelines for online assessment in emergency remote teaching during the COVID-19 pandemic. Education in Medicine Journal. 2020;12(2):59-68. https://doi.org/10.21315/eimj2020.12.2.6

14. Feldman M, Lazzara EH, Vanderbilt AA, DiazGranados D. Rater training to support high-stakes simulation-based assessments. J Contin Educ Health Prof. 2012;32(4):27986. https://doi.org/10.1002/chp.21156

15. Albanese MA. Challenges in using rater judgments. J Eval Clin Pract. 2000;6(3):305-19. https://doi.org/10.1046/ j.1365-2753.2000.00253.x

16. Blacksmith N, Willford JC, Behrend TS. Technology in the employment interview: a meta-analysis and future research agenda. Personnel Assessment and Decisions. 2016;2(1):12-20. https://doi.org/10.25035/ pad.2016.002 